\title{
Physical Ergonomics in Peripheral Nerve Block
}

\author{
Shahridan Mohd Fathil 1,2 (D), Muhamad Rasydan Abdul Ghani ${ }^{3,4}$ (D), Kung-Yen Chen ${ }^{5}$, Pinhsin Lee ${ }^{6}$, \\ Jin-De Hou $7,8, *$ and Jui-An Lin $2,5,8,9,10, *$ (D)
}

1 Department of Anesthesiology, Gleneagles Hospital Medini Johor, Iskandar Puteri 79250, Malaysia; cooldoc1971@gmail.com

2 Center for Regional Anesthesia and Pain Medicine, Wan Fang Hospital, Taipei Medical University, Taipei 116, Taiwan

3 Department of Anesthesiology and Intensive Care, Kulliyyah of Medicine, International Islamic University Malaysia, Kuantan 25200, Malaysia; rasydan@iium.edu.my

4 Sultan Ahmad Shah Medical Center, Department of Anesthesiology and Intensive Care, International Islamic University Malaysia, Kuantan 25200, Malaysia

5 Department of Anesthesiology, Wan Fang Hospital, Taipei Medical University, Taipei 116, Taiwan; 95352@w.tmu.edu.tw

6 Department of Psychiatry, Hualien Armed Forces General Hospital, Hualien 97144, Taiwan; soredia@gmail.com

7 Division of Anesthesiology, Hualien Armed Forces General Hospital, Hualien 97144, Taiwan

8 Department of Anesthesiology, School of Medicine, National Defense Medical Center, Taipei 11490, Taiwan

9 Department of Anesthesiology, School of Medicine, College of Medicine, Taipei Medical University, Taipei 110, Taiwan

10 Pain Research Center, Wan Fang Hospital, Taipei Medical University, Taipei 116, Taiwan

* Correspondence: JinDeHou805@gmail.com (J.-D.H.); juian.lin@tmu.edu.tw (J.-A.L.); Tel.: +886-3-8263151 (ext. 815672) (J.-D.H.); +886-2-29307930 (ext. 2160) (J.-A.L.)

Citation: Fathil, S.M.; Ghani, M.R.A.; Chen, K.-Y.; Lee, P.; Hou, J.-D.; Lin, J.-A. Physical Ergonomics in Peripheral Nerve Block. Appl. Sci. 2021, 11, 9736. https://doi.org/ 10.3390/app11209736

Academic Editors: Andrea Ballini, Dario Di Stasio, Antonio Boccaccio and Maria Contaldo

Received: 31 August 2021

Accepted: 11 October 2021

Published: 19 October 2021

Publisher's Note: MDPI stays neutral with regard to jurisdictional claims in published maps and institutional affiliations.

Copyright: (c) 2021 by the authors. Licensee MDPI, Basel, Switzerland. This article is an open access article distributed under the terms and conditions of the Creative Commons Attribution (CC BY) license (https:// creativecommons.org/licenses/by/ $4.0 /)$.
Abstract: The understanding of ergonomics is a vital competency for all peripheral nerve block operators. The essence of physical ergonomics for peripheral nerve block procedures can be summarised into three significant components: brain, musculoskeletal and needling. The first component includes strategies to optimise visuospatial neuroprocessing using equipment configuration. The second component reflects the careful planning of posture and position to improve procedural technique and reduce physical fatigue. The final component focuses on strategies to achieve needle beam alignment for optimal needle visualisation.

Keywords: ergonomics; peripheral nerve block; ultrasonography

\section{Introduction}

The practice of regional anaesthesia (RA) has been transformed with the advent of ultrasound guidance, and the use of this modality has become the accepted standard of care, particularly for peripheral nerve block (PNB) [1]. Ergonomics is already an established scientific discipline and can be readily applied in the design of modern anaesthesiology working practice standards [2]. The understanding of ergonomic concepts is therefore a vital competency for all PNB operators. This mini review introduces the theoretical foundations of ergonomics as applied to regional anaesthesia and discusses how this influences the conduct of PNB techniques.

\section{Conceptual Framework of Physical Ergonomics in PNB}

The International Ergonomics Association has proposed the following definition- "Ergonomics (or human factors) is the scientific discipline concerned with the understanding of interactions among humans and other elements of a system, and the profession that applies theory, principles, data, and methods to design to optimise human well-being and overall system performance" [3]. The general approach of ergonomics is thus to optimise system performance while ensuring the well-being of individuals at the workplace. 
Ergonomics in PNB can be grossly divided into organisational, cognitive and physical components. Organisational ergonomics aims to improve patient throughput in the operating theatre complex through multidisciplinary cooperation. Cognitive ergonomics aims to optimise the decision-making process to improve PNB performance. Physical ergonomics aims to improve PNB performance through optimising techniques and operator comfort [4].

The essence of physical ergonomics as applied in the context of PNB can be summarised into three significant factors: brain, musculoskeletal and needling. The brain factor requires the need to balance visual and sensory cues with the ability to orientate and direct the needle tip to the desired location. The musculoskeletal factor involves the careful planning of posture and position to optimise needle tip control and reduce physical fatigue. The needling factor focuses on selecting an effective strategy for insertion of the block needle to facilitate injection of local anaesthetic to the desired target area.

\subsection{Brain: Minimising Visuospatial Neuroprocessing Burden Using Equipment Configuration}

The success of PNB results from the accurate placement of local anaesthetics in sufficient doses via needle near a target nerve or in a fascial plane, with no or minimal complications [5].

\subsubsection{Importance of Gaze-Down Viewing}

Ultrasound-guided techniques involve the simultaneous manipulation of the ultrasound probe and the block needle in three dimensions whilst looking at a two-dimensional screen. Fine needle adjustments are necessary to achieve a good local anaesthetic spread. The image displayed on the ultrasound screen functions as a visual interface.

In minimally invasive surgery (MIS), the best task performance is obtained with the monitor located in front of the operator, at the level of the hands, allowing gaze-down viewing and alignment of the visual and motor axes [6,7]. This ergonomic position has been extensively adopted in PNB (Figure 1).

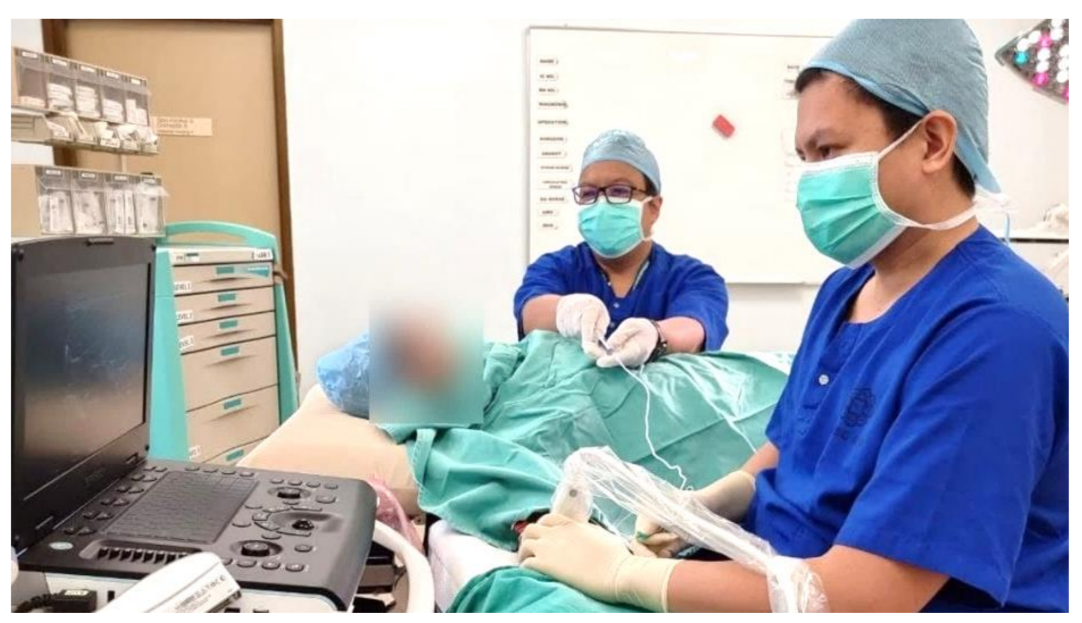

Figure 1. Monitor located in front of the operator, at the level of the hands, allowing gaze-down viewing and alignment of the visual and motor axes in front of the operator.

The monitor screen serves as a visual interface for the procedure during surgery. However, there is a dissociation between these screen images and the hand manipulations required during MIS. This dissociation requires a geometric transformation between the spatial orientation of the images seen and manipulation of the instruments. This can be minimised by adequate image quality and size and by correctly aligning the visual display information with the physical operating field (i.e., left and right as well as up and down axes) on the same side as the manipulations [8]. Similar strategies apply to PNB, where the image of the needle on the ultrasound monitor screen should provide the most accurate 
representation of the anatomical field for a particular PNB. Thus, the proceduralist should ensure that the screen is adjusted so that needle movements in vertical and horizontal axes (up/down, left/right and forwards/backwards) are correspondingly displayed on the monitor screen.

The block needle should be held in the dominant hand for optimal fine motor control, particularly in right-handed operators, who show superior motor competence in the dominant hand [9].

\subsubsection{Head-Mounted Display}

Head-mounted display (HMD) is a technology that can superimpose a visual information display over the wearer's field of view. In the first description of HMD in general anaesthesia, vital signs displayed on the HMD reduced the time required for visualising the anaesthesia workstation and allowed more time for the direct patient and surgical field monitoring [10].

When connected to the ultrasound machine, the ultrasound images can be projected to a head-mounted display (HMD) (Figure 2a,b). HMD has been shown to improve ergonomics in studies using mannikins and animal simulations by automatically aligning the axes [11,12]. In two simulated nerve block studies, blocks with HMD were faster than without [13,14]. The same group of authors [13] performed a clinical study with HMD. Regional blocks performed with HMD were significantly faster with significantly fewer head movements and attempts [15].

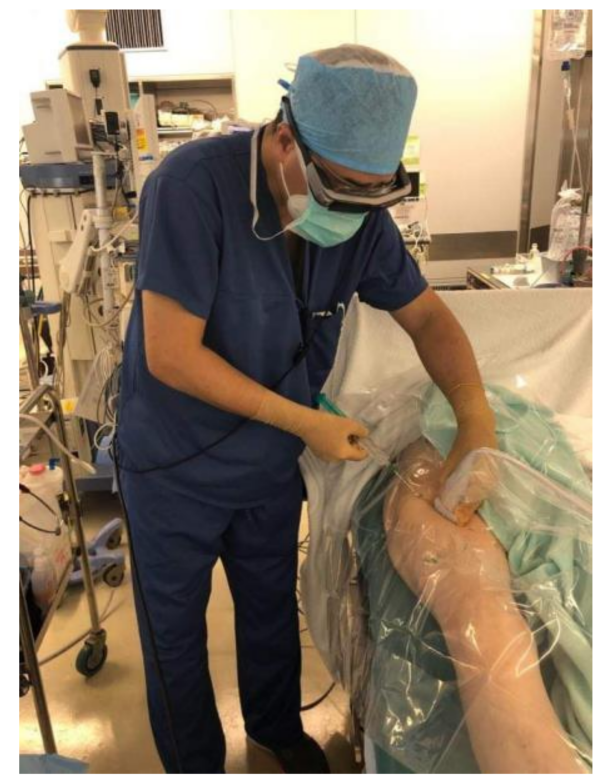

(a)

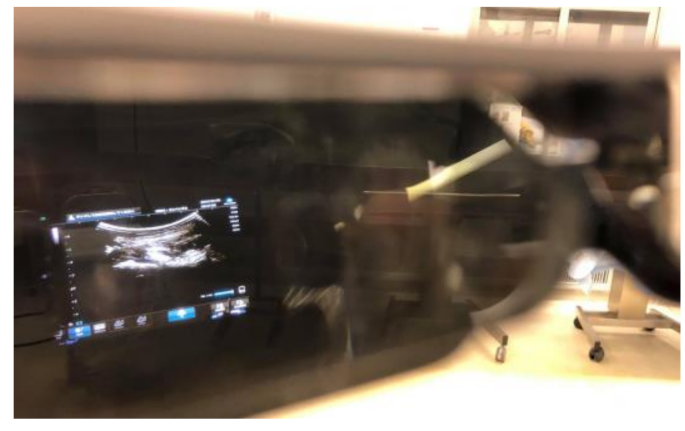

(b)

Figure 2. (a) Head-mounted display used while performing a femoral triangle block. Photo Credit: Tatsuo Nakamoto; Department of Anaesthesiology, Kansai Medical University; (b) The ultrasound image is displayed on the Epson Moverio BT-30E head-mounted display. Photo Credit: Tatsuo Nakamoto; Department of Anaesthesiology, Kansai Medical University.

The wired HMD technology used in the above references [10-15] and Figure 2a,b are attached to the ultrasound machine and may obstruct the movement of the PNB operator. In the future, wireless technology may be more ergonomic [14].

Instead of commercially available HMD, a smartphone attachment to a headset with input from the ultrasound machine has been described to facilitate simulation training [16]. A smartphone connected to a wireless ultrasound probe and attached to a flexible neck mobile phone holder has been used clinically to maintain eye-hands alignment [17]. 


\subsubsection{Visuospatial Aptitude}

Visuospatial and psychomotor skills are necessary for the performance of PNB. Visuospatial aptitude is a better predictor than the psychomotor ability for the performance of ultrasound-guided procedures [18]. Even in novices, visuospatial ability testing can predict the performance of ultrasound-guided needling [19].

Novice operators usually perform blocks poorly and without implementing basic ergonomic principles [20]. Formal training in ultrasound-guided PNB should include visuospatial processing and fundamental ergonomic factors.

One of the best possible ergonomic outcomes for visuospatial neuroprocessing in PNB is achieved by aligning the visual and motor axes, gaze-down image display and exact side placement of the needle image and needle entry.

\subsection{Environment Principles}

Operating room (OR) temperature should be at least $20^{\circ} \mathrm{C}$ to $23^{\circ} \mathrm{C}$ [21]. At the same time, relative humidity should be kept between $20 \%$ to $60 \%$ [21]. Adequate and adjustable lighting should be available. Silence is the most optimal situation while performing blocks. Noises arising from staff activities, conversations, ventilation and the anaesthetic workstation should be minimised to between $40 \mathrm{~dB}$ and $80 \mathrm{~dB}$ and for short periods only [21,22].

A standard OR should be the size of $38 \mathrm{~m}^{2}$ to $55 \mathrm{~m}^{2}$ (400 square feet to 600 square feet) with adequate ventilation of 20 air changes per hour. There should be ample space for the ultrasound, trolley, operator and assistant positioned close to the patient during the PNB performance $[23,24]$.

Operation theatre staff should don level 1 personal protective equipment (PPE) namely surgical face mask, apron, gloves and eye protection-for PNB on suspected or confirmed COVID-19 patients [25]. All block procedures should be carried out as aseptic procedures. For continuous PNB, an additional sterile gown for the operator and assistant is required [26].

\subsection{Role of Assistants}

Most PNB performances warrant a two-person technique where the operator advances the needle tip whilst an assistant administers the injectate through an attached catheter. Ergonomically, the first assistant should be located on the dominant side of the operator. Both the operator and assistant also should monitor the needle hub for blood during gentle aspiration before each aliquot of injectate given. The assistant also must observe for expansion of intended spaces on the ultrasound monitor while administering the injectate [25].

Ideally, there should be a second assistant that helps in communicating with the patient, providing physical and psychological support. The second assistant must also support the patient in the best position and help prevent movement during the procedure [26].

\subsection{Musculoskeletal: Neutral Posture and Patient Positioning}

Anaesthesiologists are at high risk of developing a work-related musculoskeletal disorder (WRMD), particularly in the neck and lower back. The most significant ergonomic risk identified was bending for a long duration [27]. Upper limb disorders affecting the hand, arm and neck are common among anaesthesiologists [28].

WRMD has an $84 \%$ to $90 \%$ incidence among ultrasound professionals. The body parts most often affected in decreasing order were shoulder, neck, wrist, back and hands. Apart from pain, the other reported symptoms included muscle spasm, inflammation, swelling, loss of sensation, numbness and clumsiness [29].

To avoid WRMD, the most important preventive measure for the PNB operator is to adopt the neutral position while performing PNB [28]. Neutral posture is a seated or standing posture balanced around the operator's centre of gravity (Figure 3). The neutral posture reduces musculoskeletal strain. The operator should avoid non-neutral postures- 
namely sustained reach, bending and twisting of the trunk; excess neck flexion, extension rotation; an uneven seated or standing weight distribution; wrist flexion or extension; and/or deviation pinch grip [29,30].

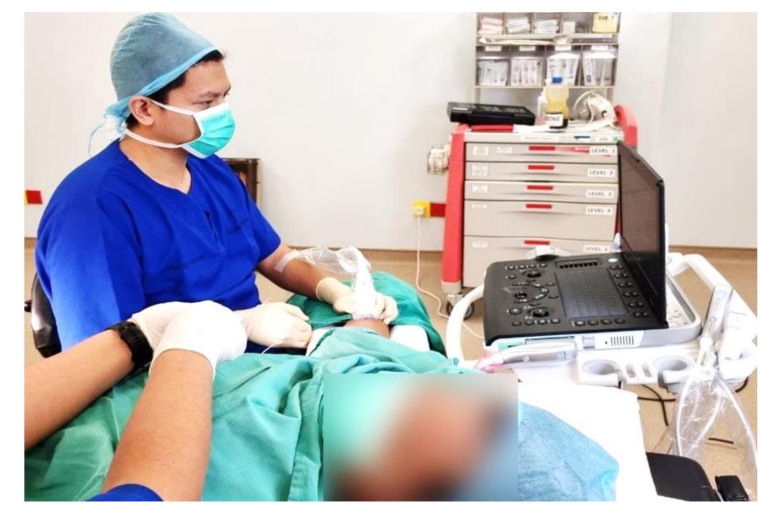

Figure 3. Neutral position while performing a mid-forearm median nerve block. The operator is in a seated balanced position using a supported chair with the ultrasound monitor in front.

The two most common improper postures are arm abduction, defined as an angle greater than $30^{\circ}$ between the torso and the upper extremity, and overreaching, which requires the operator to use the shoulder muscles (Figure 4 ). This can be avoided by moving the patient closer to the operator [29].

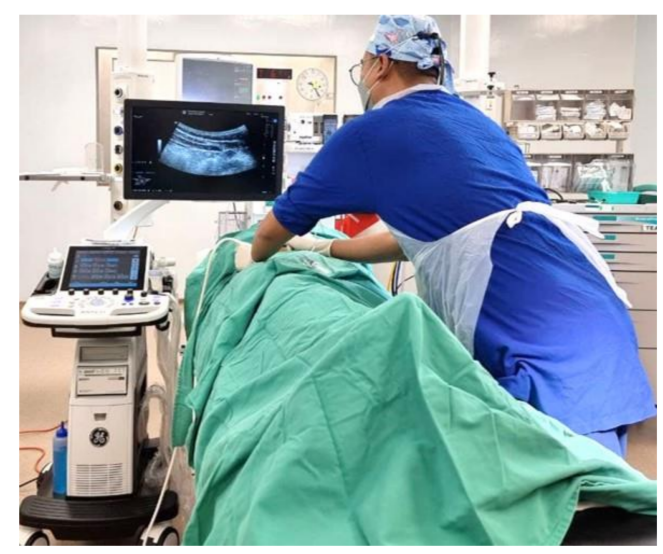

Figure 4. Improper posture: arm abduction more than $30^{\circ}$, overreaching, trunk rotation while standing from the opposite side during a transversus abdominis plane (TAP) block.

Neck flexion, extension, protraction and rotation leading to prolapsed intervertebral discs of the cervical spine and neck muscle tension can be minimised by putting the ultrasound monitor straight in front of the operator with a slight $15^{\circ}$ to $20^{\circ}$ neck flexion while viewing the monitor [29] (Figure 5a,b). Vertically adjustable articulating monitors would be helpful to achieve the ideal position for the above. 


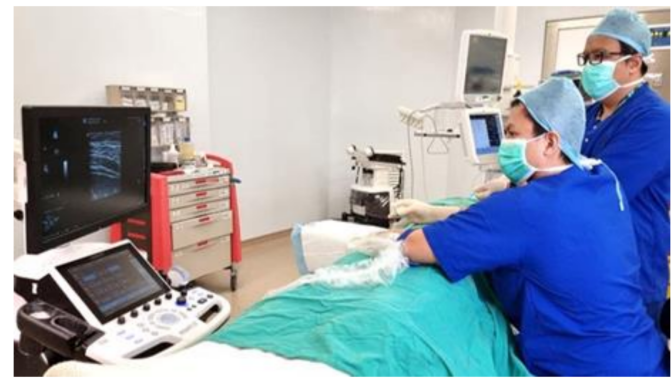

(a)

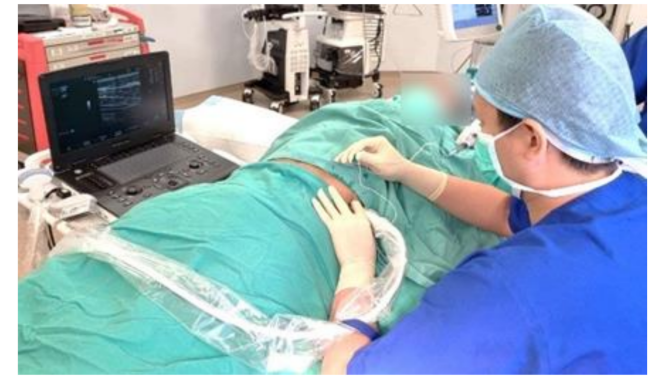

(b)

Figure 5. (a) Improper position: The operator is viewing the ultrasound monitor with a significant neck rotation to the left. (b) Proper position: The operator is viewing the ultrasound monitor straight ahead with a slight neck flexion.

Trunk bending and twisting causing back pain and disc disease are avoided by keeping the patient and ultrasound aligned on the same visual axis and adjusting the patient bed, trolley or operating table [29] (Figure 6a,b).

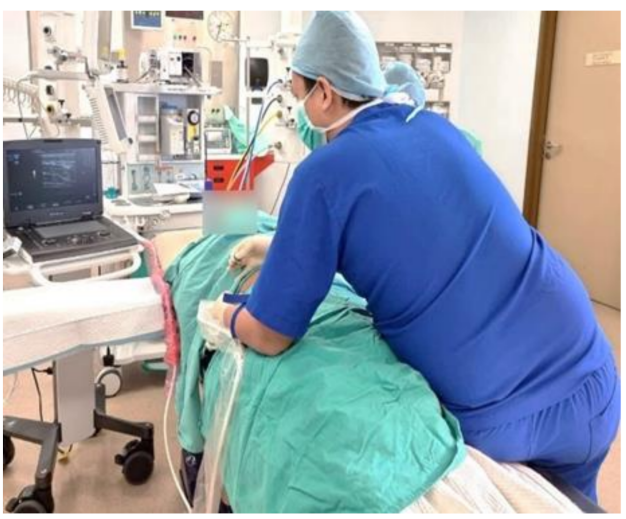

(a)

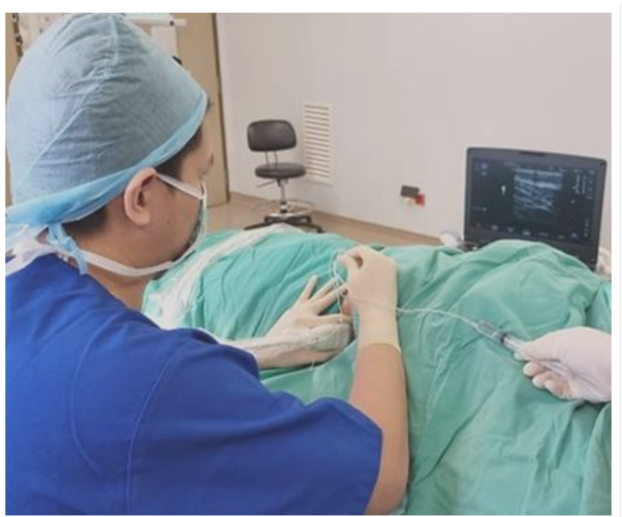

(b)

Figure 6. (a) Improper position: The operator is positioned with significant trunk bending and twisting. (b) Proper position: The operator is sitting down in a neutral position on the side of the block with ultrasound monitor in front, aligned along the visual axis.

Apart from the dominant hand, proper wrist position is also essential. Wrist flexion, extension and deviation possibly leading to increased pressure in the carpal tunnel are best avoided by assuming a neutral wrist position while holding the probe or the block needle [29] (Figure 7a,b).

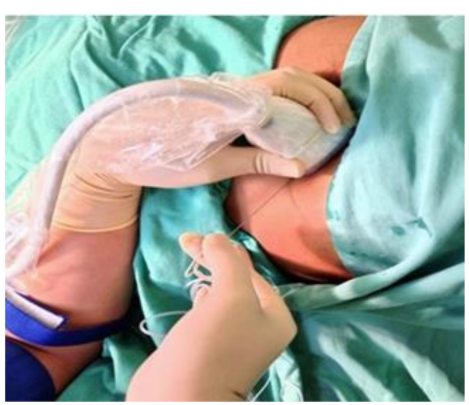

(a)

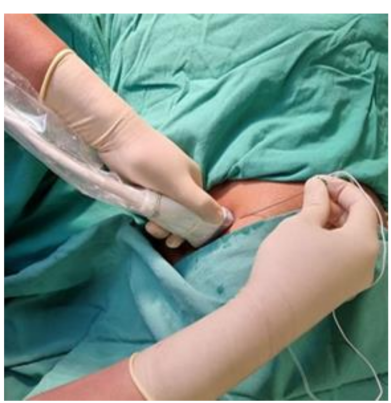

(b)

Figure 7. (a) Improper wrist flexion position. (b) Improper wrist flexion and deviation position.

A pinch grip on the probe increases the forearm muscle strain, while a palmar grip is firmer but with less strain [29] (Figure 8a,b). 


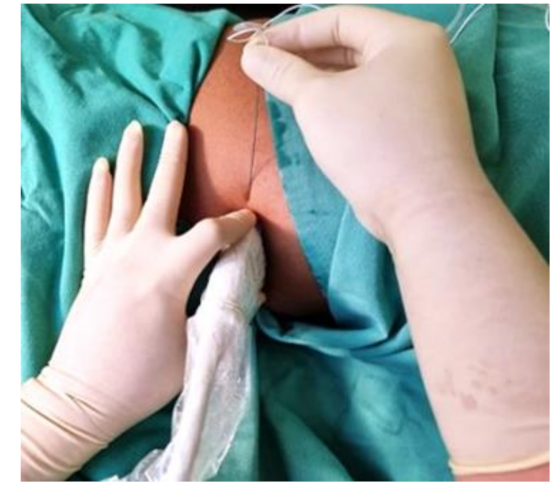

(a)

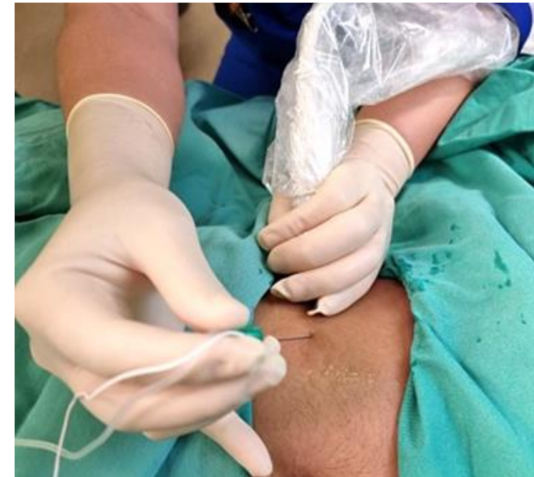

(b)

Figure 8. (a) Pinch grip while holding a probe will cause muscle strain. (b) Palmar grip while holding a probe will cause less fatigue.

Patient comfort and safety must be maintained during the procedure. The patient should rest comfortably on the operating table or trolley and access to the patient should not be obstructed. The patient's position should be safe, pain-free, and ergonomic for the specific block. For example, for the erector spinae plane block or paravertebral block, the prone position is the best but may be placed in a lateral or sitting position if prone is uncomfortable [26].

The regional anaesthesia trolley or tray should also be placed on the dominant side of the operator's handedness to avoid reaching across and overreaching to access the required instruments for the procedure [31].

\subsection{Ergonomic Needling Strategy}

Ultrasound-guided PNB can be divided into out-of-plane (OOP) and in-plane (IP) needle approaches [30]. Each technique has its advantages and disadvantages. The main concern for the OOP technique is the poor needle visibility, particularly of the needle tip. In contrast, the concern for IP is the difficulty to maintain complete needle visibility as this requires needle beam alignment [32]. Needle beam alignment is the most demanding aspect of the IP approach [33].

The IP approach can be further subdivided along the visual axis (AL) and across the visual axis (AC) (Figure 9a,b). The AL approach is associated with improved needle visualisation in pork and phantom simulations [34,35].
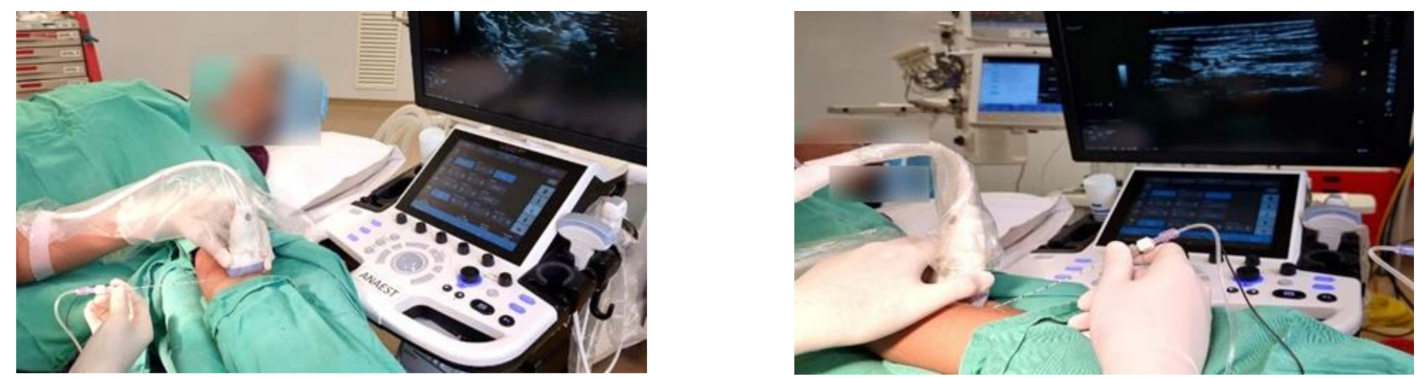

Figure 9. Cont. 


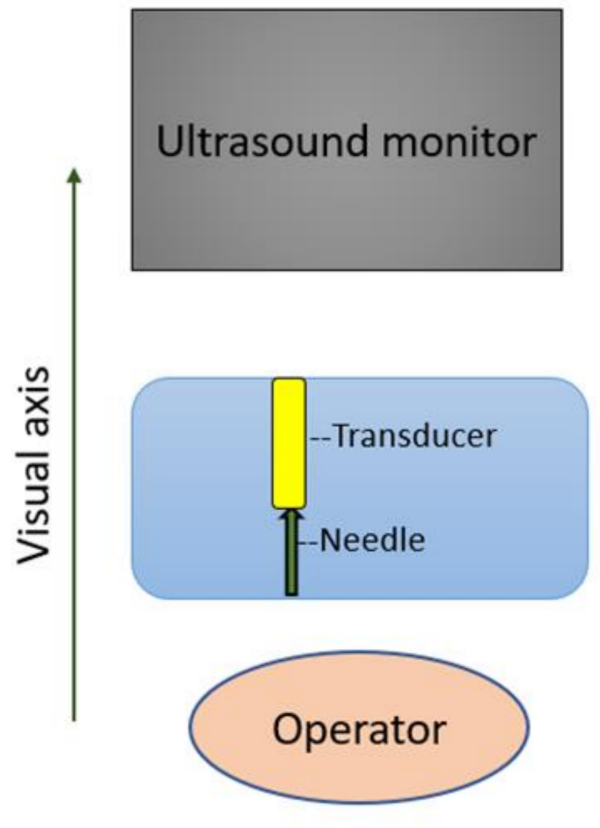

(a)

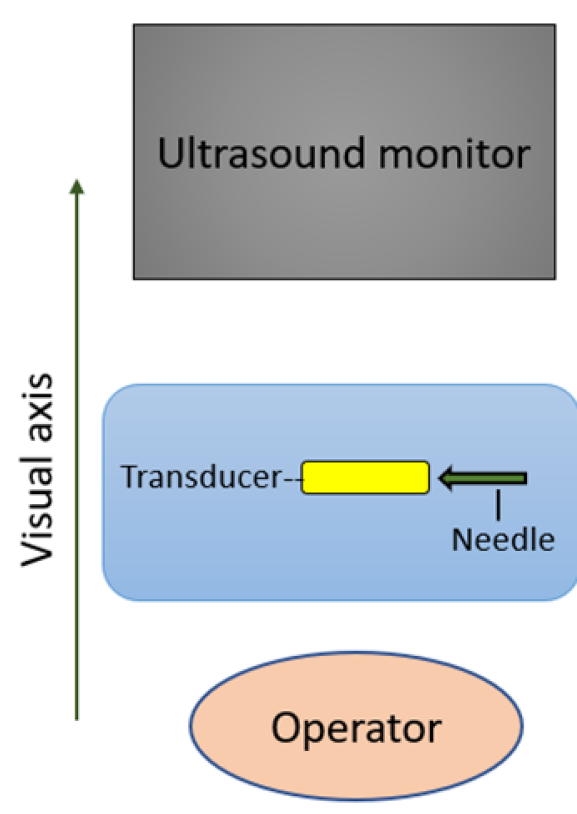

(b)

Figure 9. (a) In-plane needling where the ultrasound monitor, transducer, needle and operator are along the visual axis improves needle visualisation. (b) In-plane needling where the transducer and needle are across the visual axis impairs needle visualisation.

The needle is optimally inserted at a needle beam angle greater than $55^{\circ}$ for the best needle visibility in the IP approach [36].

It is recommended that the operator rest the fingers or part of the hand on the patient to reduce fatigue, contributing to poor needle beam alignment [33,36] (Figure 10).

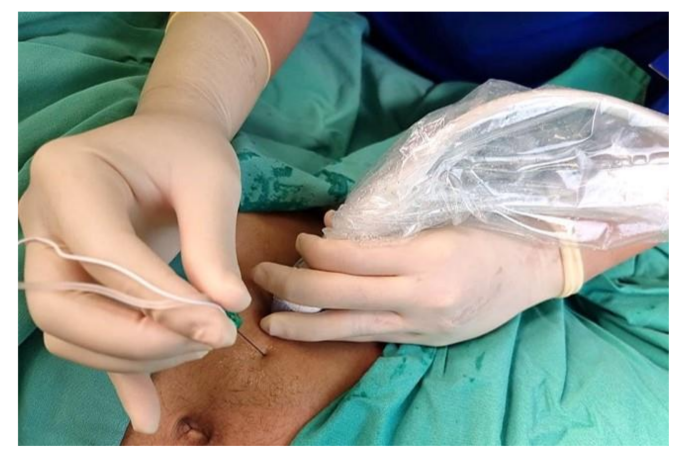

Figure 10. Resting both hands on the patient reduces fatigue and improves beam needle alignment.

The needle guide has been shown to improve the visibility of the needle at a $45^{\circ}$ angle in phantom models [37] (Figure 11). 


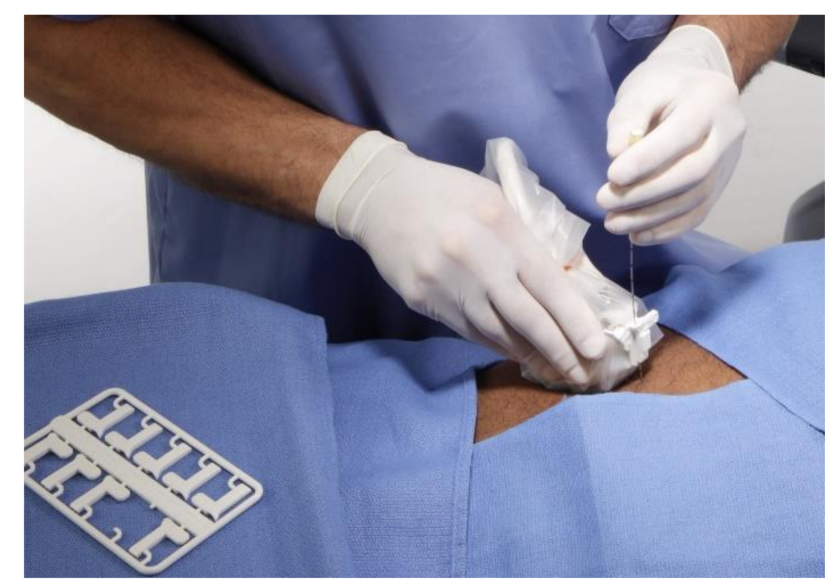

Figure 11. CIVCO needle guidance system improves beam needle alignment. Photo credit: CIVCO Medical Solutions.

There are numerous other technologies to improve needle tip visualisation. Needle construction to make it echogenic and ultrasound beam steering are technologies available in current practice [38-41]. In a 2017 review article, needle tip design, 3D/4D ultrasound, optical tracking, augmented reality, robotic assistance, image-based needle tracking, electromagnetic tracking and magnetism were discussed [42]. The above technologies are out of the context of physical ergonomics and hence will not be discussed here.

\section{Conclusions}

The adoption of the principles of physical ergonomics is essential for the efficiency of PNB performance and maintenance of the musculoskeletal well-being of the PNB operator. Improving PNB practice has the potential advantages of improving patient safety, especially in deep regional blocks. A summary (Table 1) has been made to provide the current updated concepts in PNB-related ergonomics.

Table 1. Summary of relevant ergonomics in peripheral nerve block.

1.

Optimise the Balance between Visual Input and the Cognitive Capacity to Orientate and Respond to the Combination of Visual and Physical Feedback

(a)

(b)

(c)

(d)
The monitor is located in front of the operator, at the level of the hands, allowing gaze-down viewing and alignment of the visual and motor axes.

The image of the needle on the ultrasound monitor is placed on the same side as the needle entry.

The block needle is best held in the dominant hand for better fine motor control.

The head-mounted display has been shown to improve ergonomics by abolishing the need to view the ultrasound monitor directly. 
Table 1. Cont.

(a)

(b)

(c)

(d)

(e)

(f)

(g)

(h)
Careful Planning of Posture and Position to Reduce Physical Fatigue

Neutral posture is a seated or standing posture balanced around the operator's centre of gravity.

Avoid non-neutral postures: sustained reach; bending and twisting of the trunk; excess neck flexion, extension or protraction and rotation; uneven seated or standing weight distribution; wrist flexion or extension; and/or deviation pinch grip.

Avoid improper postures: Arm abduction, defined as an angle greater than $30^{\circ}$ between the torso and the upper extremity, and overreaching, requires the operator to use the shoulder muscles.

Place the ultrasound monitor straight ahead for the operator to have a slight $15^{\circ}$ to $20^{\circ}$ neck flexion while viewing the monitor (vertically adjustable articulating monitors).

Adjust the patient bed/trolley or operating table.

Adopt neutral wrist position while holding the probe or the block needle and resting on the patient's body or using the patient's skin for support.

Utilise palmar grip; it is firmer and there is less strain.

Regional anaesthesia trolley or tray should also be placed on the dominant side of the operator's handedness to avoid reaching across and overreaching.

3.

Choosing an Effective Approach Strategy for Insertion of the Block Needle to Achieve Needle Beam Alignment for Optimal Needle Visualisation

Probe and needle should be aligned along the visual axis with an in-plane approach.

The needle is best inserted at a needle beam angle greater than $55^{\circ}$ for the best needle visibility in the in-plane approach.

Use of needle guidance, echogenic needle and ultrasound beam steering improve needle visualisation.

Author Contributions: All the authors have approved the manuscript and contributed to the study design, data analysis, interpretation of data, and writing of the paper. All authors have read and agreed to the published version of the manuscript.

Funding: This work was supported by grants from Hualien Armed Forces General Hospital, Taiwan (HAFGH-D-109008).

Institutional Review Board Statement: Not applicable.

Informed Consent Statement: Not applicable.

Data Availability Statement: Data sharing not applicable.

Acknowledgments: We would like to thank Nurfariza binti Ramli, Nurmunirah binti Mohd Sobri, Mohamed Asri bin Mohamed Zaini, Afifi Hakimi bin Aidid and Muhamad Rusmizan bin Jamalludin from the Department of Anaesthesiology and Intensive Care, Sultan Ahmad Shah Medical Centre, for their contribution, as the graphic editor (1st), photographer (2nd) and models (3rd, 4th and 5th) respectively. We would also like to thank Darell Tupper-Carey from the Department of Anaesthesia, James Paget University Hospitals NHS Foundation Trust for proofreading the manuscript.

Conflicts of Interest: The authors declare that they have no conflict of interest.

\section{References}

1. Albrecht, E.; Chin, K.J. Advances in regional anaesthesia and acute pain management: A narrative review. Anaesthesia 2020, 75, e101-e110. [CrossRef] [PubMed]

2. Alexander, G.; Staggers, N. A Systematic Review on the Designs of Clinical Technology: Findings and Recommendations for Future Research. ANS Adv. Nurs. Sci. 2009, 32, 252-279. [CrossRef] [PubMed] 
3. International Ergonomics Association (IEA) Council. Definition and Domains of Ergonomics [IEA Council Website]. Available online: https:/ / iea.cc/what-is-ergonomics/ (accessed on 1 May 2021).

4. Lin, J.A.; Blanco, R.; Shibata, Y.; Nakamoto, T. Advances of Techniques in Deep Regional Blocks. BioMed Res. Int. 2017, 7268308. [CrossRef] [PubMed]

5. Chan, V. Ultrasound Imaging for Nerve: A Standard Practice for the Future? ASA Newsl. 2005, 69, 8-9.

6. Hana, G.; Shimi, S.; Cuschieri, A. Task Performance in Endoscopic Surgery Is Influenced by Location of the Image Display. Ann. Surg. 1998, 277, 481-484. [CrossRef]

7. Omar, A.; Wade, N.; Brown, S.; Cuschieri, A. Assessing the benefits of "gaze-down" display location in complex tasks. Surg. Endosc. 2005, 19, 105-108. [CrossRef]

8. Wade, N.J. Frames of reference in vision. Minim. Invasive Ther. Allied Technol. 1996, 5, 435-439. [CrossRef]

9. Shalabi, K.M. Neuroscience of Motor Learning in Adults with Non-Dominant Hand. J. Crit. Rev. 2020, 7, 27-30.

10. Liu, D.; Jenkins, S.A.; Sanderson, P.M.; Fabian, P.; Russell, W.J. Monitoring with head-mounted displays in general anesthesia: A clinical evaluation in the operating room. Anesth. Analg. 2010, 110, 1032-1038. [CrossRef]

11. Udani, A.D.; Harrison, T.K.; Howard, S.K.; Kim, T.E.; Brock-Utne, J.G.; Gaba, D.M.; Mariano, E.R. Preliminary study of ergonomic behavior during simulated ultrasound-guided regional anesthesia using a head-mounted display. J. Ultrasound. Med. 2012, 31, 1277-1280. [CrossRef]

12. Hughey, S.; Cole, J.; Booth, G.; Longwell, J. Letter to the editor: Head-mounted display for regional anesthesia. Reg. Anesth. Pain Med. 2021, 46, 740-741. [CrossRef]

13. Przkora, R.; McGrady, W.; Vasilopoulos, T.; Gravenstein, N.; Solanki, D. Evaluation of the Head-Mounted Display for UltrasoundGuided Peripheral Nerve Blocks in Simulated Regional Anesthesia. Pain Med. 2015, 16, 2192-2194. [CrossRef]

14. Kasuya, Y.; Moriwaki, S.; Inano, C.; Fukada, T.; Komatsu, R.; Ozaki, M. Feasibility of the head-mounted display for ultrasoundguided nerve blocks: A pilot simulator study. J. Anesth. 2017, 31, 782-784. [CrossRef]

15. Przkora, R.; Mora, J.; Balduyeu, P.; Meroney, M.; Vasilopoulos, T.; Solanki, D. Ultrasound-Guided Regional Anesthesia Using a Head-Mounted Video Display: A Randomised Clinical Study. Pain Physician 2021, 24, 83-87.

16. Hyunh, K.T.; Chaika, J.; Kim, T.W. Simultaneous display of real-time ultrasound and surface landmark image. Reg. Anesth. Pain Med. 2019, 45, 481. [CrossRef]

17. Strumia, A.; Costa, F.; Pascarella, G. Felice Agrò, F.E. Eyes-hands alignment during regional anesthesia procedures: The Ultrasound Support. Saudi J. Anesth. 2021, 15, 227-228. [CrossRef]

18. Smith, H.M.; Kopp, S.L.; Johnson, R.L.; Long, T.R.; Cerhan, J.H.; Hebl, J.R. Looking into learning: Visuospatial and psychomotor predictors of ultrasound-guided procedural performance. Reg. Anesth. Pain Med. 2012, 37, 441-447. [CrossRef]

19. Shafqat, A.; Ferguson, E.; Thanawala, V.; Bedforth, N.M.; Hardman, J.G.; McCahon, R.A. Visuospatial Ability as a Predictor of Novice Performance in Ultrasound-guided Regional Anesthesia. Anesthesiology 2015, 123, 1188-1197. [CrossRef]

20. Ajmal, M.; Power, S.; Smith, T.; Shorten, G.D. Ergonomic task analysis of ultrasound-guided femoral nerve block: A pilot study. J. Clin. Anesth. 2011, 23, 35-41. [CrossRef]

21. Katz, J.D. Control of the Environment in the Operating Room. Anesth. Analg. 2017, 125, 1214-1218. [CrossRef]

22. Katz, J.D. Noise in the operating room. Anesthesiology 2014, 121, 894-898. [CrossRef]

23. The 2018 FGI Guidelines-Facility Guidelines. Available online: https://www.fgiguidelines.org/wp-content/uploads/2017/08/ SLS17_FGI_ExamProcedureOperatingImaging_170721.pdf (accessed on 1 August 2021).

24. CKAPS-ICL-Operation Theatre (Ver. Oct 2016). 1/11. Standard for Operation Theatre. Available online: http:/ / medicalprac.moh. gov.my/v2/uploads/Pelan\%20Lantai\%20dan\%20Lawatan/07OT_Oct\%202016.pdf (accessed on 1 August 2021).

25. Rational Use of Personal Protective Equipment for Coronavirus Disease (COVID-19) and Considerations during Severe Shortages. Available online: https:/ / www.who.int/publications/i/item/rational-use-of-personal-protective-equipment-for-coronavirusdisease-(covid-19)-and-considerations-during-severe-shortages (accessed on 27 September 2021).

26. Bailey, C.R.; Radhakrishna, S.; Asanati, K.; Dill, N.; Hodgson, K.; McKeown, C.; Pawa, A.; Plaat, F.; Wilkes, A. Ergonomics in the anaesthetic workplace. Anaesthesia 2021. [CrossRef]

27. Tolu, S.; Basaran, B. Work-related musculoskeletal disorders in anesthesiologists: A cross-sectional study on prevalence and risk factors. Ann. Med. Res. 2019, 26, 1406-1414. [CrossRef]

28. Leifer, S.; Choi, S.W.; Asanati, K.; Yentis, S.M. Upper limb disorders in anaesthetists-A survey of Association of Anaesthetists members. Anaesthesia 2019, 74, 285-291. [CrossRef]

29. Baker, J.P.; Coffin, C.T. The Importance of an Ergonomic Workstation to Practicing Sonographers. Ultrasound Med. 2013, 32, 1363-1375. [CrossRef]

30. Murphey, S.; Evans, K.; Merton, D. Industry Standards for the Prevention of Work-Related Musculoskeletal Disorders in Sonography. J. Diagn. Med. Sonogr. 2017, 33, 371-391. [CrossRef]

31. Ajmal, M.; Power, S.; Smith, T.; Shorten, G.D. An ergonomic task analysis of spinal anaesthesia. Eur. J. Anaesthesiol. 2009, 26, 1037-1042. [CrossRef]

32. Marhofer, P.; Harrop-Griffiths, W.; Willschke, H.; Kirchmair, L. Fifteen years of ultrasound guidance in regional anaesthesia: Part 2-Recent developments in block techniques. Br. J. Anaesth. 2010, 104, 673-683. [CrossRef]

33. Sites, B.D.; Spence, B.C.; Gallagher, J.D.; Wiley, C.W.; Bertrand, M.L.; Blike, G.T. Characterizing Novice Behavior Associated with Learning Ultrasound-Guided Peripheral Regional Anesthesia. Reg. Anesth. Pain Med. 2007, 32, 107-115. [CrossRef] 
34. Speer, M.; McLennan, N.; Nixon, C. Novice Learner In-Plane Ultrasound Imaging Which Visualisation Technique? Reg. Anesth. Pain Med. 2013, 38, 350-352. [CrossRef]

35. Wilson, J.M.B.; Germain, G.; Vaghadia, H.; Tang, R.; Sawka, A. In-plane ultrasound-guided needle insertion ALONG or ACROSS the visual axis hand positions. Br. J. Anaesth. 2014, 113, 717-722. [CrossRef] [PubMed]

36. Chin, K.J.; Perlas, A.; Chan, V.M.S.; Brull, R. Needle Visualization in Ultrasound-Guided Regional Anesthesia: Challenges and Solutions. Reg. Anesth. Pain Med. 2008, 33, 532-544. [CrossRef] [PubMed]

37. Ueshima, H.; Kitamura, A. The use of a needle guide kit improves the stability of ultrasound-guided techniques. J. Anesth. 2015, 29, 803-804. [CrossRef] [PubMed]

38. Hebard, S.; Hocking, G. Echogenic technology can improve needle visibility during ultrasound-guided regional anesthesia. Reg. Anesth. Pain Med. 2011, 36, 185-189. [CrossRef] [PubMed]

39. Abbal, B.; Choquet, O.; Gourari, A.; Bouic, N.; Massone, A.; Biboulet, P.; Bringuier, S.; Capdevila, X. Enhanced visual acuity with echogenic needles in ultrasound-guided axillary brachial plexus block: A randomized, comparative, observer-blinded study. Minerva Anestesiol. 2015, 81, 369-378. [PubMed]

40. Uppal, V.; Sondekoppam, R.V.; Ganapathy, S. Effect of beam steering on the visibility of echogenic and non-echogenic needles: A laboratory study. Can. J. Anaesth. 2014, 61, 909-915. [CrossRef] [PubMed]

41. Prabhakar, C.; Uppal, V.; Sondekoppam, R.V. Effect of Beam Steering on Echogenic and Nonechogenic Needle Visibility at $40^{\circ}$, $50^{\circ}$, and $60^{\circ}$ Needle Insertion Angles. Anesth. Analg. 2018, 126, 1926-1929. [CrossRef]

42. Scholten, H.J.; Pourtaherian, A.; Mihajlovic, N.; Korsten, H.H.M.; Bouwman, R.A. Improving needle tip identification during ultrasound-guided procedures in anaesthetic practice. Anaesthesia 2017, 72, 889-904. [CrossRef] 